\title{
Surprisingly high sensitivity of copper nanoparticles toward coordinating ligands: consequences for the hydride reduction of benzaldehyde
}

\author{
Xavier Frogneux, ${ }^{\mathrm{a}, \mathrm{b}}$ Ferenc Borondics, ${ }^{\mathrm{c}}$ Stéphane Lefrançois, ${ }^{\mathrm{c}}$ Florian D’Accriscio, ${ }^{\mathrm{a}, \mathrm{b}}$ Clément \\ Sanchez, ${ }^{\mathrm{a}, \mathrm{b}}$ Sophie Carenco ${ }^{\mathrm{a}, \mathrm{b}, *}$
}

\begin{abstract}
Functionalized copper nanoparticles are widely used as catalysts; however, identification of the catalytically active species remains a challenge. In this study we investigate hydride-assisted reduction reactions with special focus on the structural evolution of copper nanoparticles in the presence of phosphine and nitrogen-based ligands. These compounds are commonly used as stabilizing agents, therefore are important in the context of other catalytic reactions as well. In particular, we investigate the case of tri-n-butylphosphine. Our findings show that ultrasmall nano-objects are formed as key intermediates to produce catalytically active species in the hydrosilylation of benzaldehyde into the corresponding silyl alcohol. Moreover, we found that the strength of the hydride donor is essential for the formation of the active catalysts. Therefore, this work unveils the previously overlooked high sensitivity of copper nanoparticles toward coordinating ligands in the context of catalysis.
\end{abstract}

\section{Introduction}

Among the variety of metallic nanoparticles (NPs), copper NPs are made from a cheap and abundant metal, allowing scale-up in industry. They feature specific properties such as a plasmon band in the infrared range, high electrical and thermal conductivity and interesting catalytic performances, e.g. for methanol production. ${ }^{1}$ In particular, they catalyze the chemical reduction of various moieties (carbonyl derivatives, alkynes, alkenes, nitro-compounds). ${ }^{2-11}$ Nonetheless, due to their high sensitivity to oxidation, fabrication routes for Cu NPs are not as well-documented as for Ag or Au NPs. In order to obtain pure $\mathrm{Cu}(0)$ nanoparticles, colloidal syntheses are of interest as they allow working in an organic solvent with a large variety of ligands, enabling the tuning of the capping species at the surface of the nanoparticles. ${ }^{12-17}$ The reactivity of the nanoparticles can be controlled by the interaction between the ligand and the metallic center. ${ }^{18-22}$ In some cases, ligands can be detrimental to the integrity of the NPs due to the leaching of metal-ligand complexes into the medium, as it has been thoroughly studied for Pd-based catalytic systems. ${ }^{23-25}$ In the case of Cu-based NPs, leaching has been observed in some reactions but, so far, leached species were not considered as potential catalytic species. ${ }^{26-29}$

In the present study, Cu NPs were produced by colloidal synthesis in oleylamine, following a previously reported procedure. ${ }^{15}$ Their surface was characterized under air-free atmosphere by FTIR, revealing the presence of unexpected $N$ oleylacetamide moieties at the nanoparticles surface. Hydrosilylative reduction of benzaldehyde was performed with

\footnotetext{
Sorbonne Université, CNRS, Collège de France, Laboratoire de Chimie de la Matière Condensée de Paris, 4 Place Jussieu, F-75005 Paris, France. E-mail: sophie.carenco@sorbonne-universite.fr

${ }^{b .}$ PSL University, Collège de France, CNRS, Laboratoire de Chimie de la Matière Condensée de Paris, 11 Place Marcelin Berthelot, Paris, France.

SMIS Beamline, Soleil synchrotron, 91190 Saint-Aubin.

+ Electronic Supplementary Information (ESI) available: experimental methods, additional catalysis data and FTIR, NMR, ESI-MS and TEM.
}

the $\mathrm{Cu}$ NPs as catalysts and the formation of products was monitored in situ using an attenuated total reflectance infrared cell especially designed for air-sensitive nanoparticles. We showed that the addition of a second ligand (tri- $n$ butylphosphine, 1,8-diazabicyclo[5.4.0]undec-7-ene or oleylamine) was modulating the catalytic activity of the nanoparticles. While all these tested ligands induced a significant leaching of copper species into the solution from the nanoparticles, only the tri- $n$-butylphosphine provided active catalytic species. Moreover, such species were only formed with strong enough hydride donors such as phenylsilane. Leaching of copper from the nanoparticles was not sufficient by itself to allow the catalytic reduction of benzaldehyde. Rather, formation of active species demanded an adequate hydride source. This may explain why the facile leaching of copper in the presence of coordinating ligands was overlooked so far in many works using copper nanoparticles as catalysts.

\section{Results and Discussion}

Surface capping agent of copper nanoparticles prepared with oleylamine

Copper nanoparticles were prepared by reducing $\left[\mathrm{Cu}(\mathrm{acac})_{2}\right]$ in oleylamine (OAm) at $250^{\circ} \mathrm{C}$ for $2 \mathrm{~h}$ under inert atmosphere (see experimental section). ${ }^{15}$ The NPs were isolated with four cycles of washing and centrifugation and dried under a $\mathrm{N}_{2}$ flow. X-ray diffraction on powder (XRD) confirmed the fcc$\mathrm{Cu}(0)$ phase with a crystallite average size of $13 \mathrm{~nm}$ according to the Debye-Scherrer formula. Transmission Electron Microscopy (TEM) showed the presence of polydisperse nanoparticles of $35 \pm 10 \mathrm{~nm}$ in diameter (Figure $1 \mathrm{~A}, \mathrm{~B}$ and S1 in SI). 


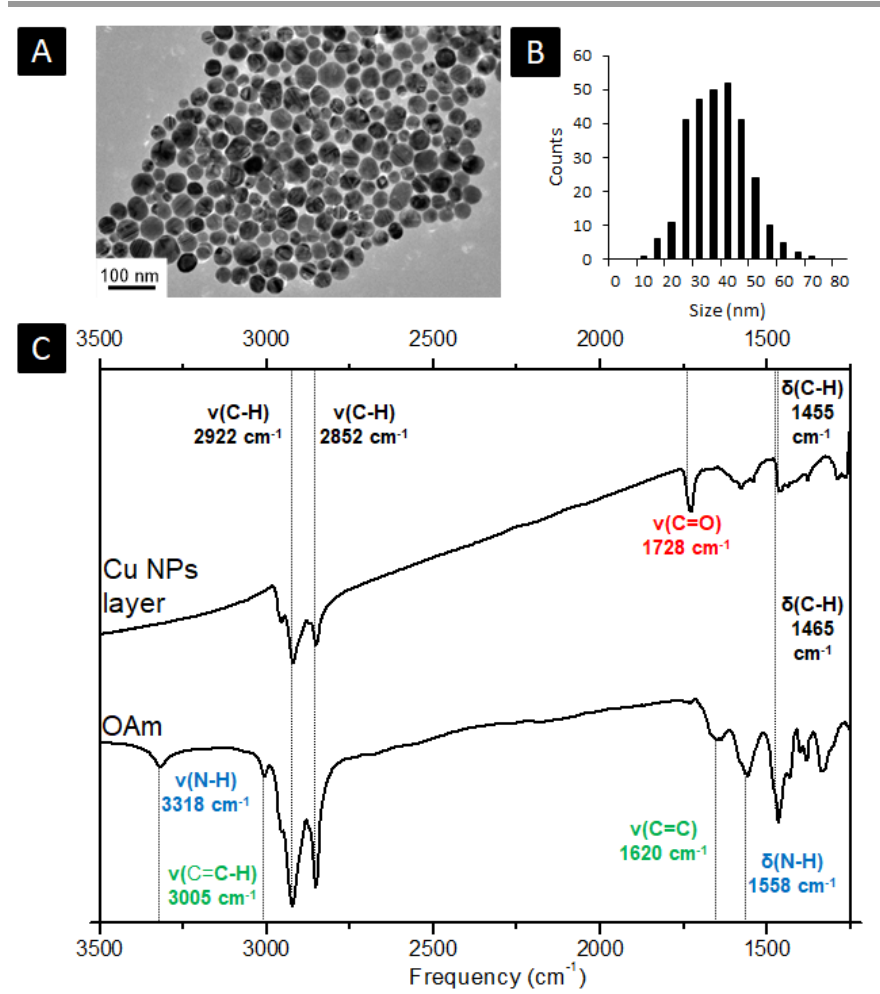

Figure 1 - (A) TEM of the Cu NPs. (B) Histogram of diameters for Cu NPs. (C) FTIR spectrum of Cu NPs layer (top) and oleylamine (bottom) measured under iner
atmosphere.

The identification of surface species stabilizing the copper nanoparticles was performed by Fourier-transformed infrared spectroscopy (FTIR) in a tailor-made air-tight Teflon cell designed for measurement in attenuated total reflection (ATR) mode (see experimental section). In the glovebox, a solution of the nanoparticles was drop-casted on a silicon single-crystal wafer. The wafer was inserted and sealed in the cell, allowing measurements under inert conditions.

Figure $1 \mathrm{C}$ shows FTIR of the copper nanoparticles compared with pure oleylamine, which was expected to be the main capping ligand around the nanoparticles. As expected, alkyl chains were detected on the nanoparticles through the $\mathrm{C}-\mathrm{H}$ vibration bands at 2922 and $2852 \mathrm{~cm}^{-1}$ and the $\mathrm{C}-\mathrm{H}$ deformation mode at $1465 \mathrm{~cm}^{-1}$ slightly shifted at $1455 \mathrm{~cm}^{-1}$ for the copper nanoparticles. The characteristic signals of the free amino group of oleylamine $\left(\mathrm{v}(\mathrm{N}-\mathrm{H})\right.$ at $3318 \mathrm{~cm}^{-1}$ and $\delta(\mathrm{N}-$ $\mathrm{H})$ at $1558 \mathrm{~cm}^{-1}$ ) could not be found on the nanoparticles spectrum; and no $-\mathrm{OH}$ group was detected in the 3000$4000 \mathrm{~cm}^{-1}$ area (see $\mathrm{SI}$, Figure S4). Moreover, the alkenes absorption bands $\left(\mathrm{V}(\mathrm{C}=\mathbf{C}-\mathbf{H})\right.$ at $3005 \mathrm{~cm}^{-1}$ and $\mathrm{v}(\mathrm{C}=\mathrm{C})$ at $1650 \mathrm{~cm}^{-1}$ ) were also not observed on the spectrum. Noticeably, the spectrum of the NPs layer showed an absorption band at $1728 \mathrm{~cm}^{-1}$ that could indicate the presence of a carbonyl moiety.

As a complementary analysis, ${ }^{1} \mathrm{H}$ NMR analysis was performed on the supernatant of the reaction (prior to washing steps) (see SI, Figure S2). A multiplet at $5.35 \mathrm{ppm}$ was detected, corresponding to alkene moieties. The absence of the corresponding IR band on the NPs could indicate either that the ligands coordinated to the nanoparticles did not contain alkene moieties, or that these moieties were in strong interaction with the surface. Moreover, based on the ${ }^{1} \mathrm{H} N M R$ spectrum, it is clear that the amino group of oleylamine, which should have appeared as a triplet at $2.64 \mathrm{ppm}\left(\mathrm{N}-\mathrm{CH}_{2}\right)$ and a signal at $1.1 \mathrm{ppm}\left(\mathrm{N}-\mathrm{H}_{2}\right)$, is completely absent. Further, the presence of a singlet at $1.97 \mathrm{ppm}$ indicated a possible condensation of oleylamine with an acetylacetonate fragment, consistent with the presence of a $\mathrm{v}(\mathrm{C}=\mathrm{O})$ band in FTIR. The supernatant of the reaction was also analyzed by gas chromatography coupled to a mass spectrometer (GC-MS). It showed the presence of a major product of mass $309 \mathrm{~g} \cdot \mathrm{mol}^{-1}$. In relation with the bands detected in the FTIR spectrum, this was attributed to $\mathrm{N}$-oleylacetamide $\left(\mathrm{CH}_{3}-\mathrm{CO}-\mathrm{NH}-\mathrm{R}\right.$, with $R$ as the alkyl chain of oleylamine), formed during the heating process of the NPs synthesis from the condensation of oleylamine with an acetyl fragment coming from the decomposition of acetylacetonate. ${ }^{30,31} \mathrm{H}$ from this $\mathrm{N}-\mathrm{H}$ moiety was detected as a "free" species by ${ }^{1} \mathrm{H}$ NMR of the supernatant by a broad signal at $2.60 \mathrm{ppm}$ (Figure S2), although the $\mathrm{N}-\mathrm{H}$ vibration was not observed by FTIR for the species coordinated to the surface.

It should be noted that this product was also detected in the analogous synthesis of nickel nanoparticles, although in that case it was not the major product. ${ }^{31,32}$ Altogether, an unexpected surface ligand, $\mathrm{N}$-oleylacetamide, formed during the synthesis of the nanoparticles and acted as the main native capping ligand on the surface of the nanoparticles.

\section{Influence of tri- $n$-butylphosphine on the reactivity of copper nanoparticles for the reduction of benzaldehyde}

The copper-catalyzed reduction of benzaldehyde was investigated in solution, without and with additional tri- $n$ butylphosphine. Tri- $n$-butylphosphine was selected, among commercial phosphines, as a coordinating ligand, expected to improve the colloidal stability of the nanoparticles in solution, as observed with other metal nanoparticles, ${ }^{33-35}$ and also for its ability to modify the electronic properties of the copper nanoparticles.

The nanoparticles were engaged in the reduction of benzaldehyde by hydrosilylation using phenylsilane in tetrahydrofuran (THF) (Scheme 1). Hydrosilanes represent a very convenient hydride source for the reduction of carbonyl compounds since they can be used in very mild conditions, limiting the formation of over-reduction products and allowing chemoselective and/or asymmetric reactions. ${ }^{36}$ The silicon moiety can then be easily removed in the presence of fluoride to recover the alcohol. ${ }^{37}$ Among them, phenylsilane is considered a strong hydride donor, and was selected for the first series of experiment.

First attempts using the nanoparticles as prepared showed no catalytic activities. Tri- $n$-butylphosphine $\left(\mathrm{P}(n-\mathrm{Bu})_{3}, 1\right.$ equiv. vs. $\mathrm{Cu}$ ) was added as a co-catalyst: a dark-reddish suspension formed, suggesting an improved colloidal stability of the nanoparticles. As a result the complete reduction of benzaldehyde was observed within $1 \mathrm{~h}$ at room temperature (RT), using 0.6 mol\% of copper vs. benzaldehyde. The ${ }^{1} \mathrm{H}$ NMR spectrum of an aliquot of the mixture revealed the complete conversion of benzaldehyde into the corresponding silylated alcohol (Table 1, entry 1 , vide supra). Noticeably, upon the addition of phenylsilane and benzaldehyde to suspension of 
Cu NPs/P $(n-B u)_{3}$, strong bubbling and heating of the solvent was immediately observed. Bubbles came from the dehydrogenation of the phenylsilane (producing $\mathrm{H}_{2}$, detected by ${ }^{1} \mathrm{H}$ NMR), which is a competitive reaction.

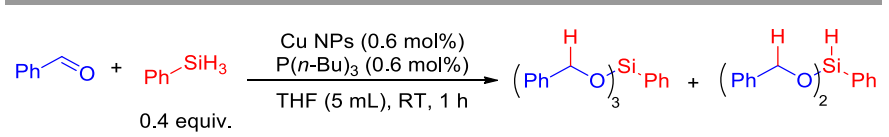

Scheme 1 - Cu-catalyzed hydrosilylation of benzaldehyde with phenylsilane

In order to understand the role of the phosphine, the reaction was reproduced in the air-tight FTIR cell: the nanoparticles were drop-casted on the silicon wafer as before, and a THF solution containing benzaldehyde, phenylsilane and $\mathrm{P}(n-\mathrm{Bu})_{3}$ in molar ratio 1:0.4:0.006 (identical to the ratio used in the standard protocol) was added onto the nanoparticles layer. Figure $2 \mathrm{~A}$ shows the series of spectra collected immediately before (first spectrum) and after addition of the solution ( $c a$. $0.1 \mathrm{~mL}$ ), over $2000 \mathrm{~s}$. Several bands were observed on the initial spectrum, coming from THF $\left(1969 \mathrm{~cm}^{-1}, 1460 \mathrm{~cm}^{-1}\right.$, $\left.1365 \mathrm{~cm}^{-1}, 1289 \mathrm{~cm}^{-1}\right)$, benzaldehyde $\left(1704 \mathrm{~cm}^{-1}\right.$, two bands at 1597 and $1585 \mathrm{~cm}^{-1}, 1310 \mathrm{~cm}^{-1}$; blue dots) and phenylsilane $\left(2157 \mathrm{~cm}^{-1}\right.$, red dot). After addition of the reaction mixture in the cell, the FTIR spectra were dominated by the absorption peaks of the solvent and reactant. Product formation was detected through the appearance of bands at $1594 \mathrm{~cm}^{-1}$, $1497 \mathrm{~cm}^{-1}$ and $1379 \mathrm{~cm}^{-1}$ (Figure 2A, green dots). Figure 2B shows the time evolution of the integrated intensities of the bands at $1704 \mathrm{~cm}^{-1}(\mathrm{v}(\mathrm{C}=\mathrm{O}))$ and $2156 \mathrm{~cm}^{-1}(\mathrm{v}(\mathrm{Si}-\mathrm{H}))$. Their fast decrease indicated that the reaction in the cell was completed within $500 \mathrm{~s}$. Moreover, the monotonic decrease of the benzaldehyde and phenylsilane concentration (Figure 2B) suggested no induction time at the time-scale of a few tens of seconds. As a control experiment, injection of the reaction mixture deprived of $\mathrm{P}(n-\mathrm{Bu})_{3}$ lead - as expected - to no reduction of the benzaldehyde, although a partial decomposition of the silane was observed (see SI, Figure S5).
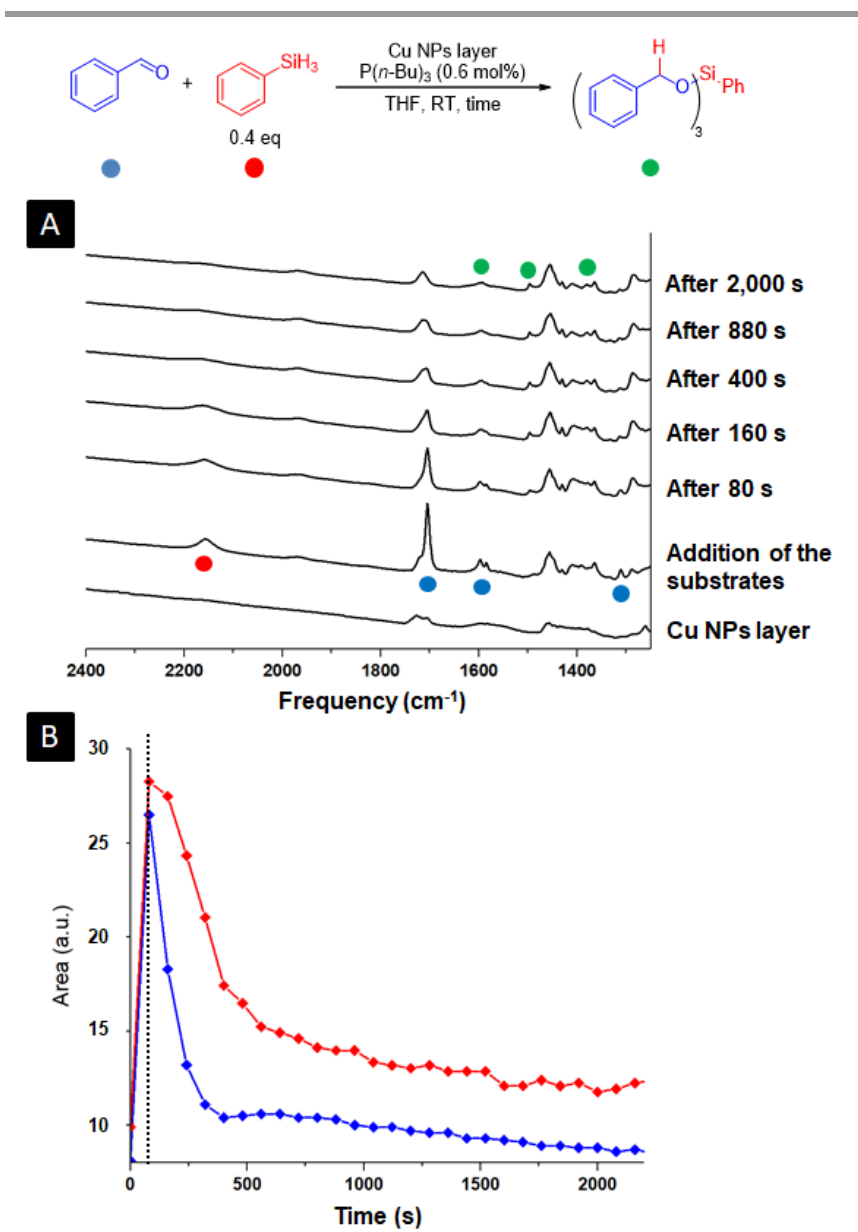

Figure $\mathbf{2}$ - Reduction of benzaldehyde with phenylsilane. (A) Series of FTIR spectra (B) Integration of the carbonyl (blue) and hydride (red) absorption vs.
time. Dotted line indicates the addition of the solution.

As a partial conclusion, the combination of both the $\mathrm{Cu}$ NPs and $\mathrm{P}(n-\mathrm{Bu})_{3}$ was essential to observe a catalytic activity (Table 1, entries 1-4). The absence of an induction time at a $10 \mathrm{~s}$ time scale, as well as the immediate release of $\mathrm{H}_{2}$ observed experimentally upon addition of the benzaldehyde into the nanoparticles suspension, indicated that the active catalytic species were formed from $\mathrm{Cu} \mathrm{NPs}$ and $\mathrm{P}(n-\mathrm{Bu})_{3}$ prior the addition of the reactants. This phosphine effect is not specific to $\mathrm{P}(n-\mathrm{Bu})_{3}$ as other phosphines (tricyclohexylphosphine, triphenylphosphine) or the diphosphine (1,2bis(diphenylphosphino)benzene showed comparable reactivities after $15 \mathrm{~min}$ of reaction time (see ESI, Table S1). The more sterically hindered tri-tert-butylphosphine and the tridentate phosphine 1,1,1tris(diphenylphosphinomethyl)ethan proved to be very poor ligands for this catalytic reaction. 


$$
\text { Table } 1 \text { - Reduction of benzaldehyde with various catalysts }
$$

\begin{tabular}{ccc}
\hline Entry & catalyst & Benzaldehyde conversion $\left({ }^{1} \mathrm{H}\right.$ NMR $)$ \\
\hline 1 & $\mathrm{Cu} \mathrm{NPs}+\mathrm{P}(n-\mathrm{Bu})_{3}$ & $>99 \%$ \\
2 & none & $N R$ \\
3 & $\mathrm{Cu} \mathrm{NPs}$ & $N R$ \\
4 & $\mathrm{P}(n-\mathrm{Bu})_{3}$ & $N R$ \\
5 & {$\left[\mathrm{Cu}(\mathrm{acac})_{2}\right]$} & $N R$ \\
6 & {$\left[\mathrm{Cu}(\mathrm{acac})_{2}\right]+\mathrm{P}(n-\mathrm{Bu})_{3}$} & $>99 \%$ \\
\hline
\end{tabular}

Reaction conditions: in a $10 \mathrm{~mL}$ closed tube, catalyst $(0.6 \mathrm{~mol} \%, 0.016 \mathrm{mmol}$ ) in $\operatorname{THF}(5 \mathrm{~mL}), \mathrm{P}(n-\mathrm{Bu})_{3}(0.6 \mathrm{~mol} \%, 0.016 \mathrm{mmol}), \mathrm{PhCHO}(5 \mathrm{mmol})$, hydride source $(6 \mathrm{mmol}) . \mathrm{NR}$ : no conversion of benzaldehyde.

In order to gain insights into the catalyst nature, the activity of nanoparticles was compared with that of copper complexes. The initial $\left[\mathrm{Cu}(\mathrm{acac})_{2}\right]$ compound used for the nanoparticles synthesis proved to be an inefficient catalyst for this reaction (Table 1, entry 5). However, in the presence of 1 equiv. of $P(n-$ $\mathrm{Bu})_{3}$, the blue solution quickly turned yellow to dark in seconds, suggesting the formation of $\mathrm{Cu}$ NPs (Figure S13), showed the same reactivity than the nanoparticles for benzaldehyde reduction (Table 1 , entry 6). The in situ formation of $\mathrm{Cu}$ NPs from Cul and $\mathrm{PhSiH}_{3}$ has recently been reported by Sharma et al. in the $\mathrm{C}-\mathrm{N}$ bond reaction formation of carbonyls with amines. ${ }^{38}$

The observations described above using nanoparticles as catalysts (e.g. the brightening of the red color at the addition of the phenylsilane) were reminiscent of the formation of copper hydride species stabilized by phosphine ligands. ${ }^{39,40}$ In fact, among the variety molecular metallic complexes known to promote hydrosilylative reduction of carbonyl derivatives, ${ }^{36,41,42} \mathrm{Cu}(\mathrm{I})$ and $\mathrm{Cu}(\mathrm{II})$ complexes proved to be potent candidates because of the formation of copper hydride species, stabilized by electron-rich phosphines. ${ }^{43-47}$ However the in situ formation of nanoparticles or clusters, such as Stryker's reagent, is rarely discussed ${ }^{38}$ whereas they can be active in various reactions. ${ }^{1,48,49}$ Thus, we investigated the nature of the active species and the possibility of leaching in the current reaction.

\section{Description of the active catalytic species}

Leaching is a recurring issue when using NPs in catalysis, as the generated solvated metal complex or clusters, in our case $\mathrm{Cu}$, could as well be catalysts for the reaction. Thus, we performed a leaching test, using a less reactive hydrosilane, TMDS (1,1,3,3-tetramethyldisiloxane), in order to stop the reaction at a partial conversion after 15 minutes (Scheme 2).

Benzaldehyde was reacted with TMDS in the presence of $\mathrm{Cu}$ $\mathrm{NPs} / \mathrm{P}(n-\mathrm{Bu})_{3}$ as catalyst for $15 \mathrm{~min}$ (Scheme $\left.2 \mathrm{~A}\right)$. Then, half of the crude (B) was centrifuged at 10,000 g for 25 min whereas the other half (dark red) was kept intact (D). ${ }^{50}$ The colorless supernatant (C) was carefully collected from (B) and $\mathrm{PhSiH}_{3}$ was added, yielding a light yellow solution. Similarly, $\mathrm{PhSiH}_{3}$ was added to flask (D), yielding a bright red solution (E). In both cases, $\mathrm{PhSiH}_{3}$ addition was quickly followed by the formation of bubbles and a slight heating of the solution, meaning that active copper complexes were still present in the nanoparticle-free solution (C). After 15 min of stirring, ${ }^{1} \mathrm{H}$ NMR of both solutions showed similar conversion of benzaldehyde into the silylated alcohol. According to TEM, the initial Cu NPs (see Figure $1 \mathrm{~A}$ ) were already etched in numerous smaller NPs $(<5 \mathrm{~nm}$ ) after addition of the TMDS (Scheme 2D) and their morphology was even farther from the starting one after addition of $\mathrm{PhSiH}_{3}$ (Scheme $2 \mathrm{E}$ ).

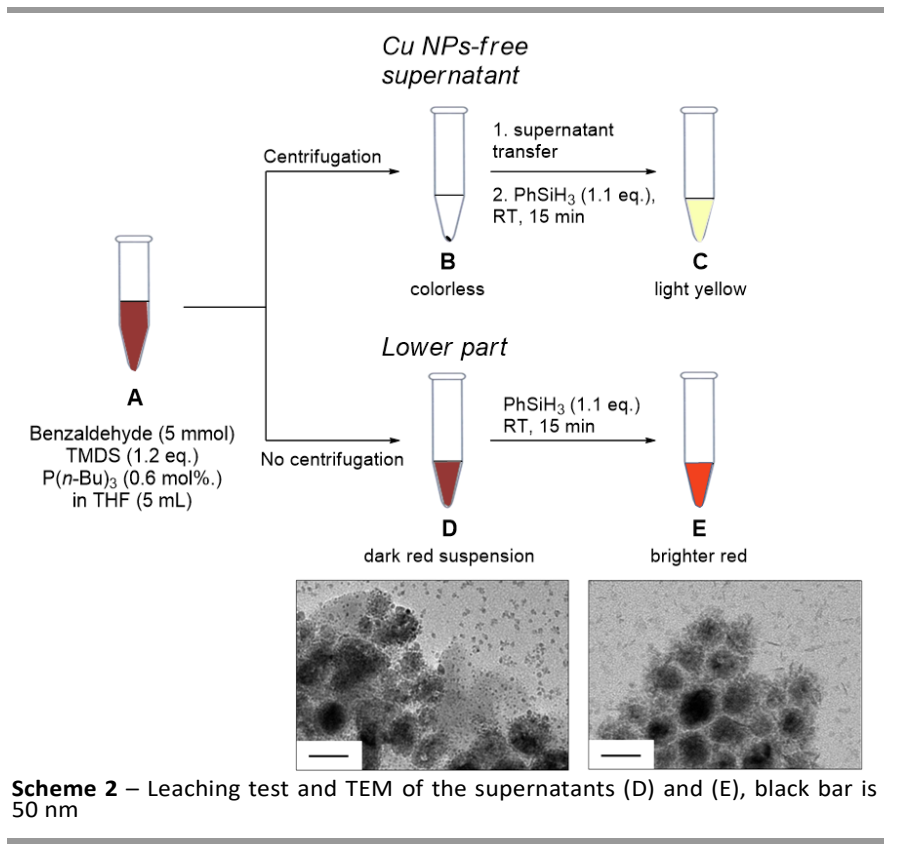

Inductively Coupled Plasma Mass Spectrometry (ICP-MS) of the supernatant $(C)$ revealed that it contained about $5 \%$ of the initial copper: homogeneous copper species and/or small clusters were produced from the NPs via a leaching phenomenon. It is to be noted that the system $\left\{\left[\mathrm{Cu}(\mathrm{acac})_{2}\right]+\right.$ $\left.\mathrm{P}(n-\mathrm{Bu})_{3}\right\}$ is also efficient at the loading of the detected species by ICP in the supernatant (approx. $0.03 \mathrm{~mol} \%$ ). At this point, two hypotheses can be considered: (i) Cu NPs act as a copper source to release catalytically active copper hydride molecular complexes/clusters or (ii) both $\mathrm{Cu}$ NPs and leached copper hydride species are catalytically active.

The leaching was further studied by analyzing clean $\mathrm{Cu} N \mathrm{NP} / \mathrm{P}(n-\mathrm{Bu})_{3}$ suspensions in THF after $18 \mathrm{~h}$ at RT. $\mathrm{Cu} N \mathrm{NP} / \mathrm{P}(n-\mathrm{Bu})_{3}$ in a 1:1 ratio already showed a non-negligible amount of small Cu NPs compared to the initial ones $(<5 \mathrm{~nm}$ versus $40 \mathrm{~nm}$ ) (Scheme $3 \mathrm{~A}$ ). Increasing the quantity of phosphine in solution led to even more etching of the Cu NPs. At 250 equiv. of $\mathrm{P}(n-\mathrm{Bu})_{3}$, only nanoscaled species smaller than $5 \mathrm{~nm}$ were found on the TEM grid. Noticeably, the same effect occurred by replacing the phosphine by a typical ligand for copper complexes, DBU (1,8-diazabicyclo[5.4.0]undec-7ene), ${ }^{51-53}$ or even by oleylamine ${ }^{13}$ (Scheme 3B). However, neither of these suspensions of leached copper nanoparticles showed catalytic property for the reduction of benzaldehyde with phenylsilane. This means that the formation of leached nanoscaled species was not sufficient to produce catalytically active species. Rather, the phosphine was required as a cocatalyst. 


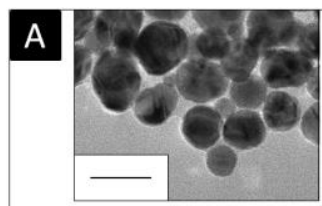

0

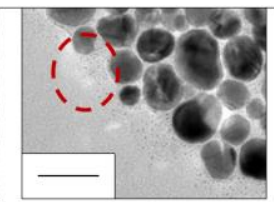

1

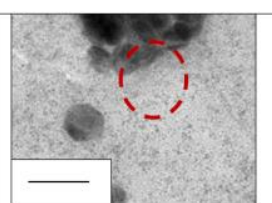

8

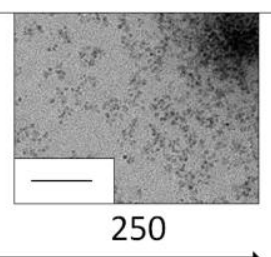

250

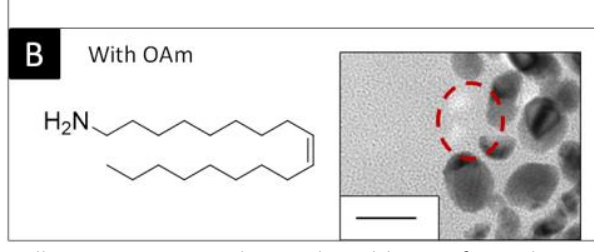

$\mathrm{P}(n-\mathrm{Bu})_{3} / \mathrm{Cu}$ molar ratio

With DBU
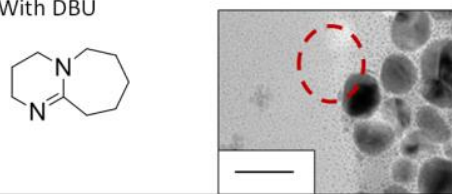

Scheme 3 - Formation of smaller Cu NPs in THF due to the addition of coordinating ligands. (A) Influence of the quantity of P( $n$-Bu $)_{3}$ on Cu NPs. From left to right: $n$ $\mathrm{P}(n-\mathrm{Bu})_{3} ; 1$ equiv. per $\mathrm{Cu}$ atom; 8 equiv. per Cu atom; 250 equiv. per $\mathrm{Cu}$ atom; (B) Influence of two other ligands. Left: 1 equiv. of DBU per Cu atom; right: 1 equiv. of $\mathrm{OAm}$ per Cu atom. Scale bars are $50 \mathrm{~nm}$. Red circles are a guide to the eye, indicating the newly-formed species.

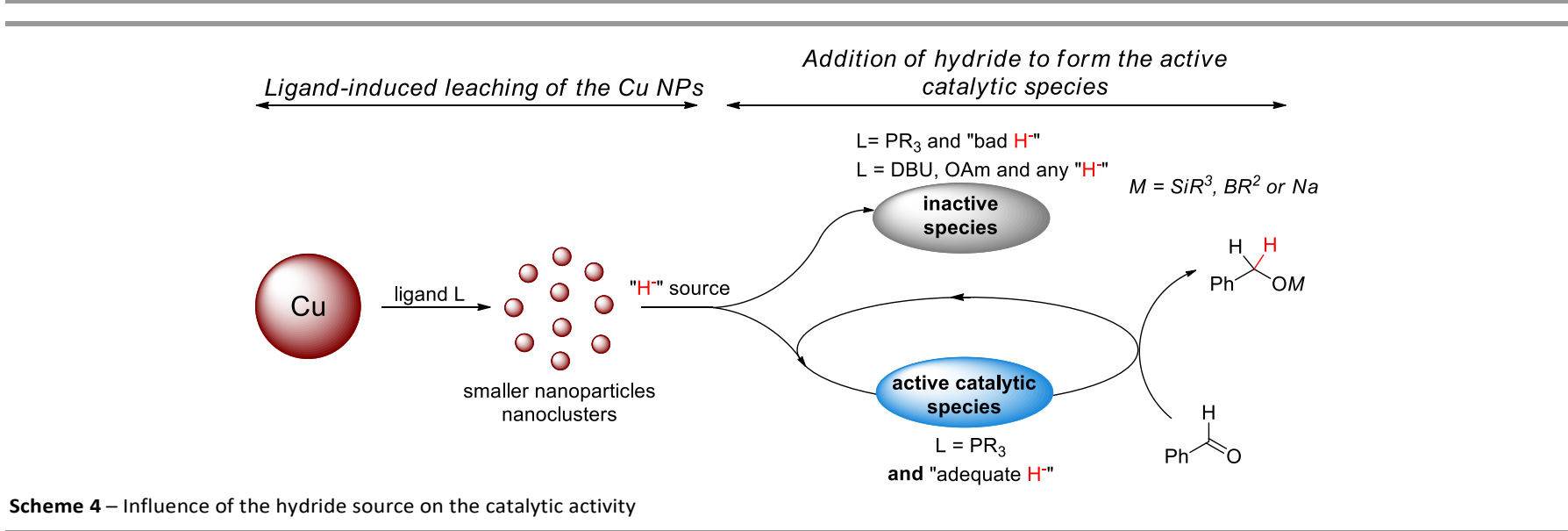

To identify more precisely the active catalytic species, copper species resulting from the phosphine presence were analyzed by electrospray-ionization mass spectroscopy (ESI-MS). These species were produced by stirring Cu NPs ( $3 \mathrm{mg}$ ) for $24 \mathrm{~h}$ in pure $\mathrm{P}(n-\mathrm{Bu})_{3} \quad(3 \mathrm{~mL})$. After washing cycles with THF and centrifugation, the powder was redispersed in THF as a red suspension. Copper species with nuclearity of 1 to 5 stabilized by $\mathrm{P}(n-\mathrm{Bu})_{3}$ were detected: e.g. $\mathrm{Cu}\left(\mathrm{PBu}_{3}\right)_{2} \quad(\mathrm{~m} / \mathrm{z}=469)$, $\left(\mathrm{PBu}_{3}\right)_{2} \mathrm{Cu}_{5}(\mathrm{CN})_{4}(\mathrm{~m} / \mathrm{z}=825)$ (see $\mathrm{SI}$, Figure $\left.\mathrm{S} 14,15\right)$. Larger species could not be detected by our experimental setup but were observed by TEM (Scheme 3A).

In order to determine if the leaching was a cause of the nanoscale of initial copper nanoparticles, the reaction was also explored with an ultrapure copper foil (purity $>99.99 \%$ ) as the copper species. The copper foil alone (ca. $50 \mathrm{mg}$ ) was not able to catalyze the reduction of benzaldehyde with phenylsilane at $20{ }^{\circ} \mathrm{C}$ after $18 \mathrm{~h}$. However, in the presence of $\mathrm{P}(n-\mathrm{Bu})_{3}$ in a catalytic amount $(0.6 \mathrm{~mol} \%)$, the colorless solution turned light yellow and the septum of the flask was swollen, indicating the formation of gaseous $\mathrm{H}_{2}$. The ${ }^{1} \mathrm{H}$ NMR analysis revealed that ca. $20 \%$ of benzaldehyde was converted into various silylated species. Additionally, the ${ }^{31} \mathrm{P}\left\{{ }^{1} \mathrm{H}\right\}$ NMR showed drastic decrease and broadening of the signal of free $\mathrm{P}(n-\mathrm{Bu})_{3}$ (at $-32 \mathrm{ppm}$ ) (see $\mathrm{SI}$, Figure S19), indicating a possible coordination of the phosphine in cluster-type complexes. The control reactions were performed without $\mathrm{Cu}$ foil or without $\mathrm{P}(n-\mathrm{Bu})_{3}$, resulting in no conversion of benzaldehyde. At this point, it appeared that the source of copper was not critical regarding the existence of leaching.

The generation of copper-hydride species is a key step in the copper-catalyzed reduction of carbonyl compounds (Scheme $4)^{43,54}$ and appears to be related to the nature of the coordinating ligands $\left(\mathrm{P}(n-\mathrm{Bu})_{3}, \mathrm{OAm}, \mathrm{DBU}\right)$. So far, we demonstrated that several coordinating ligands were able to generate leached species from the Cu NPs but only phosphinestabilized copper species were able to act as catalysts for the hydrosilylative reduction of benzaldehyde (Scheme 4, right).

Copper-hydride species require stabilization, which is usually done with phosphines or $\mathrm{N}$-heterocyclic carbenes. ${ }^{48,55}$ Among the three ligands studied here, we propose that only $\mathrm{P}(n-\mathrm{Bu})_{3}$ stabilizes them properly. To test this hypothesis, different hydride sources were investigated in the presence of $\mathrm{P}(n-\mathrm{Bu})_{3}$ (Scheme 4). 
Influence of the hydride source on the activity of the copper catalyst

Various hydride sources were tested for the reduction of benzaldehyde, in similar conditions as previously $(0.6 \mathrm{~mol} \%$ of $\left.\mathrm{Cu} \mathrm{NPs} / \mathrm{P}\left(n-\mathrm{Bu}_{3}\right), \mathrm{RT}, 18 \mathrm{~h}\right)$. Table 2 shows the results ordered by family and strength of hydrides. Benzaldehyde was fully reduced using $\mathrm{Ph}_{2} \mathrm{SiH}_{2}$ or $(\mathrm{EtO})_{3} \mathrm{SiH}$ (entries 2,3) and only partially with TMDS (31\%, entry 4$)$.

Hydrosilanes with a lower hydride donating ability proved to be unreactive in these conditions (entries 5-8). $\mathrm{NaH}$ acted as a catalyst for the disproportionation of benzaldehyde into benzyl benzoate, according to the Tishchenko reaction ${ }^{56}$ (entry 9), which occurs quicker than the direct reduction of benzaldehyde.

Boron-based hydride donor such as $\mathrm{NaBH}_{4}$ or 9borabicyclo[3.3.1]nonane (9-BBN-H) were also highly reactive for the reduction of benzaldehyde (entries 10, 11). Interestingly, ammonium formate was not able to reduce benzaldehyde by hydrogenation (entry 12 ). ${ }^{57-59}$

Compared to the other reductants, ammonium formate was also more detrimental to the integrity of the nanoparticles, according to TEM observation after the catalytic test (SI, Table S2).

Finally, bubbling $\mathrm{H}_{2}$ in the system did not result in any conversion of benzaldehyde (entry 13). Noticeably, the reduction of benzaldehyde was highly dependent on the hydride choice. This means that the formation of phosphinestabilized copper species was not sufficient to obtain catalytically active species. Thus, the adequate combination between the right ligand and a strong enough hydride donor seems mandatory to reach a catalytic activity.

\section{Conclusions}

This work highlights the ligand sensitivity of the applications of $\mathrm{Cu}$ NPs in catalytic reduction reactions and reactivates the question of the homogeneous or heterogeneous state of the catalytically active species, as it has been the case for Pt-based catalysts for the hydrosilylation of olefins. ${ }^{60-62}$ In the presence of a phosphine (such as $\left.\mathrm{P}\left(n-\mathrm{Bu}_{3}\right)\right)$, these NPs proved to be active for the reduction of benzaldehyde in the presence of a strong enough hydride source.

The activity of this system is based on the rapid partial leaching of the NPs, which act as a copper reservoir, releasing phosphine-stabilized copper species that seem to be the catalytically active species. Leaching was not systematically providing active catalytic species: rather, these should present a suitable ligand (phosphine) in combination with a suitable hydride source (silylated or not).

We propose this as the reason why many catalysis studies on ligand-stabilized copper nanoparticles do not report leached molecular species as the active catalytic species, although these may form in the reaction medium. From a more fundamental perspective, model studies of the interaction of phosphines with planar copper surfaces (e.g. single-crystals) may inform on the elementary steps of the leaching process.
Table $\mathbf{2}$ - Reactivity of selected hydrides for the reduction of benzaldehyde and their effects on the Cu NPs.

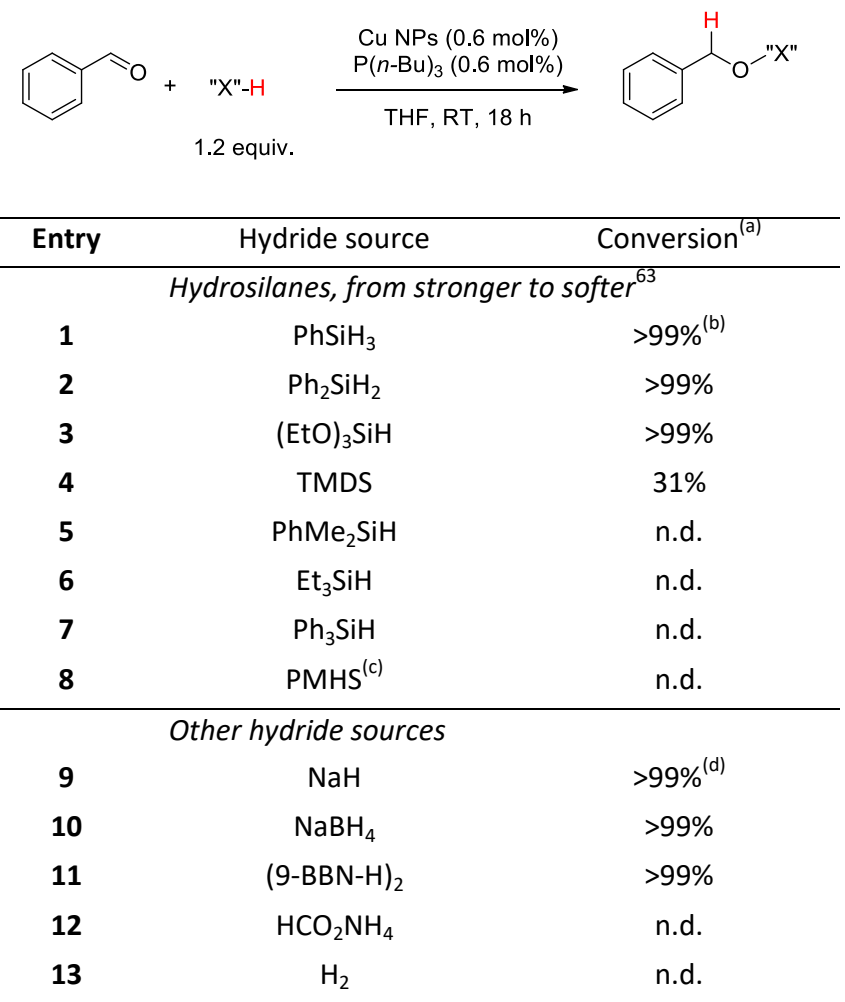

Reaction conditions: in a $10 \mathrm{~mL}$ closed tube, Cu NPs ( $0.6 \mathrm{~mol} \%, 0.016 \mathrm{mmol}$ of $\mathrm{Cu}$ ) dispersed in THF $(5 \mathrm{~mL}), \mathrm{P}(n-\mathrm{Bu})_{3}(0.6 \mathrm{~mol} \%, 0.016 \mathrm{mmol}), \mathrm{PhCHO}(5 \mathrm{mmol})$, hydride source $(6 \mathrm{mmol})$. (a) ${ }^{1} \mathrm{H}$ NMR yield given for the conversion of benzaldehyde to the corresponding alcohol; n.d. = not detected (b) Complete after 20 min. (c) PMHS = polymethylhydrosiloxane. (d) benzaldehyde was fully converted into benzyl benzoate.

\section{Conflicts of interest}

There are no conflicts to declare.

\section{Acknowledgements}

This work was performed in the framework of Idex ANR-10IDEX-0001-02 PSL*. The "Cellule Energie" of CNRS provided financial support for IR instrumentation. Sorbonne Université, CNRS and Collège de France are acknowledged for financial support. The synchrotron SOLEIL is acknowledged for beamtime allocation on beamline SMIS (under proposal 20160209 and 20170383) and for the use of chemistry laboratory facilities onsite. We are very thankful to Christophe Sandt and Paul Dumas for helpful discussions about ATR measurements. Denis Lesage (Sorbonne University), Domitille Giaume and Claudine Keil (IRCP, Chimie Paris) are acknowledged for their expertise in ESI-MS, ICP-MS and GCMS, respectively.

\section{Notes and references}

1 M. B. Gawande, A. Goswami, F.-X. Felpin, T. Asefa, X. Huang, R. Silva, X. Zou, R. Zboril and R. S. Varma, Chem. Rev., 2016, 116, 3722-3811. 

2012, 33, 10-13. X. Yang, H. Zhong, Y. Zhu, H. Jiang, J. Shen, J. Huang and C. Li, J. Mater. Chem. A Mater. Energy Sustain., 2014, 2, 9040-9047. A. K. Sasmal, S. Dutta and T. Pal, Dalt. Trans., 2016, 45, 3139-3150. Dhakshinamoorthy, S. Navalon, D. Sempere, M. Alvaro and H. Garcia, Chem. Commun., 2013, 49, 49-51. T. Subramanian and K. Pitchumani, Catal. Sci. Technol., 2012, 2, 296-300.

F. Arena, K. Barbera, G. Italiano, G. Bonura, L. Spadaro and F. Frusteri, J. Catal., 2007, 249, 185-194.

C. S. Chen, J. H. Wu and T. W. Lai, J. Phys. Chem. C, 2010, 114, 15021-15028.

S. Natesakhawat, J. W. Lekse, J. P. Baltrus, P. R. Ohodnicki, B. H. Howard, X. Deng and C. Matranga, ACS Catal., 2012, 2, 1667-1676.

A. Fedorov, H. Liu, H. Lo and C. Copéret, J. Am. Chem. Soc., 2016, 138, 6-11. 2426-2430.

C. Barrière, K. Piettre, V. Latour, O. Margeat, C.-O. Turrin, B. Chaudret and P. Fau, J. Mater. Chem., 2012, 22, 2279.

S. Duman and Ö. Saim, ChemCatChem, 2017, 9, 25882598.

M. A. Ben Aissa, B. Tremblay, A. Andrieux-Ledier, E. Maisonhaute, N. Raouafi and A. Courty, Nanoscale, 2015, 7, 3189-3195.

S. Carenco, Y. Hu, I. Florea, O. Ersen, C. Boissière, N. Mézailles and C. Sanchez, Chem. Mater., 2012, 24, 41344145.

M. Salavati-niasari, Z. Fereshteh and F. Davar, Polyhedron, 2009, 28, 126-130.

D. Adner, S. Möckel, M. Korb, R. Buschbeck, T. Rüffer, S. Schulze, L. Mertens, M. Hietschold, M. Mehring and H. Lang, Dalt. Trans., 2013, 42, 15599-15609.

I. Cano, M. a Huertos, A. M. Chapman, G. Buntkowsky, T. Gutmann, P. B. Groszewicz and P. W. N. M. van Leeuwen, J. Am. Chem. Soc., 2015, 137, 7718-27.

N. Almora-barrios, I. Cano and P. W. N. M. Van Leeuwen, ACS Catal., 2017, 7, 3949-3954.

K. R. Kahsar, D. K. Schwartz and J. W. Medlin, J. Am. Chem. Soc., 2014, 136, 520-526.

I. Schrader, J. Warneke, J. Backenko and S. Kunz, J. Am. Chem. Soc., 2014, 137, 905-912.

I. Cano, A. M. Chapman, A. Urakawa and P. W. N. M. Van Leeuwen, J. Am. Chem. Soc., 2014, 136, 2520-2528.

D. Astruc, F. Lu and J. R. Aranzaes, Angew. Chemie - Int. Ed. 2005, 44, 7852-7872.

B. H. Lipshutz, S. Tasler, W. Chrisman, B. Spliethoff and B. Tesche, J. Org. Chem., 2003, 68, 1177-1189.

M. Diéguez, O. Pàmies, Y. Mata, E. Teuma, M. Gómez, F. Ribaudo and P. W. N. M. Van Leeuwen, Adv. Synth. Catal., 2008, 350, 2583-2598.

J. Zhang, C. Yu, S. Wang, C. Wan and Z. Wang, Chem. Commun., 2010, 46, 5244.

M. J. Albaladejo, F. Alonso and M. Yus, Chem. - A Eur. J., 2013, 19, 5242-5245.

W. Zhang, F. Guo, F. Wang, N. Zhao, L. Liu, J. Li and Z. Wang, Org. Biomol. Chem., 2014, 12, 5752-5756. S. K. Movahed, M. Dabiri and A. Bazgir, Appl. Catal. A Gen., 2014, 481, 79-88.

S. Wang, Y. Yu, X. Chen, H. Zhu, P. Du, G. Liu, L. Lou, H. Li and W. Wang, Tetrahedron Lett., 2015, 56, 3093-3096.

S. Carenco, S. Labouille, S. Bouchonnet, C. Boissière, X. F. Le Goff, C. Sanchez and N. Mézailles, Chem. - A Eur. J., 2012, 18, 14165-14173.

K. X. Bhattacharyya, C. Pradel, P. Lecante and N. Mézailles, Chem. - A Eur. J., 2017, 23, 9352-9361.

J. Tang, F. Redl, Y. Zhu, T. Siegrist, L. E. Brus and M. L. Steigerwald, Nano Lett., 2005, 5, 543-548. J. Y. Choi, S. J. Lee, W. S. Seo and H. Song, CrystEngComm, 2016, 18, 6069-6075. J. Park, E. Kang, S. U. Son, H. M. Park, M. K. Lee, J. Kim, K. W. Kim, H. J. Noh, J. H. Park, C. J. Bae, J. G. Park and T. Hyeon, Adv. Mater., 2005, 17, 429-434.

S. Díez-González and S. P. Nolan, Acc. Chem. Res., 2008, 41, 349-358.

A. M. Dilauro, W. Seo and S. T. Phillips, J. Org. Chem., 2011, 76, 7352-7358.

M. Kumar, V. Bhatt, O. S. Nayal, S. Sharma, V. Kumar, M. S. Thakur, N. Kumar, R. Bal, B. Singh and U. Sharma, Catal. Sci. Technol., 2017, 7, 2857-2864.

W. S. Mahoney, D. M. Brestensky and J. M. Stryker, J. Am. Chem. Soc., 1988, 110, 291-293. B. A. Baker, Ž. V. Bošković and B. H. Lipshutz, Org. Lett., 2007, 10, 289-292. W. Sattler, S. Ruccolo, M. Rostami Chaijan, T. Nasr Allah and G. Parkin, Organometallics, 2015, 34, 4717-4731. A. Rit, A. Zanardi, T. P. Spaniol, L. Maron and J. Okuda, Angew. Chemie - Int. Ed., 2014, 53, 13273-13277. C. Deutsch, N. Krause and B. H. Lipshutz, Chem. Rev., 2008, 108, 2916-2927. K. Motokura, D. Kashiwame, A. Miyaji and T. Baba, Org. Lett., 2012, 14, 2642-2645.

K. Motokura, N. Takahashi, D. Kashiwame, A. Miyaji and T. Baba, Catal. Sci. Technol., 2013, 3, 2392-2396. A. Y. Houghton, V. A. Karttunen, E. Piers and H. M. Tuononen, Chem. Commun., 2014, 50, 1295-1298. L. Zhang and Z. Hou, Chem. Sci., 2013, 4, 3395-3403. R. S. Dhayal, W. E. van Zyl and C. W. Liu, Acc. Chem. Res., 2016, 49, 86-95.

49 A. W. Cook, Z. R. Jones, G. Wu, S. L. Scott and T. W. Hayton, J. Am. Chem. Soc., 2018, 140, 394-400.

50 J. A. Widegren and R. G. Finke, J. Mol. Catal. A. Chem., 2003, 198, 317-341.

51 R. Watari, Y. Kayaki, S. Hirano, N. Matsumoto and T. Ikariya, 2015, 1369-1373. B. F. Thakur and G. Sekar, Synthesis, 2009, 16, 2785-2789. R. Watari, N. Matsumoto, S. Kuwata and Y. Kayaki, ChemCatChem, 2017, 9, 4501-4507.

J.-T. Issenhuth, F.-P. Notter, S. Dagorne, A. Dedieu and S. Bellemin-Laponnaz, European J. Org. Chem., 2010, 529541. 

6904-6907.

P. Selvam, S. U. Sonavane, K. Mohapatra and R. V Jayaram, Tetrahedron Lett., 2004, 45, 3071-3075.

M. Kidwai, V. Bansal, A. Saxena and S. Mozumdar, Tetrahedron Lett., 2006, 47, 4161-4165.

59 A. Saha and B. Ranu, J. Org. Chem., 2008, 73, 6867-6870.

60 T. Galeandro-Diamant, M. L. Zanota, R. Sayah, L. Veyre, C. Nikitine, C. De Bellefon, S. Marrot, V. Meille and C.

Thieuleux, Chem. Commun., 2015, 51, 16194-16196.

61 M. A. Rivero-Crespo, A. Leyva-Pérez and A. Corma, Chem. A Eur. J., 2017, 23, 1702-1708.

62 B. P. S. Chauhan and A. Sarkar, Dalt. Trans., 2017, 46, 8709-8715.

63 M. Horn, L. H. Schappele, G. Lang-Wittkowski, H. Mayr and A. R. Ofial, Chem. - A Eur. J., 2013, 19, 249-263. 